\title{
A CONTRIBUIÇÃO DA MÚSICA NA EDUCAÇÃO INFANTIL
}

\author{
Fernanda Viana Pinheiro ${ }^{1}$ \\ Joanice Batista de Arruda ${ }^{2}$ \\ Maria Cristina Gusmão Ferreira ${ }^{3}$ \\ Rosiane Cristina de França Azevedo Franco 4
}

RESUMO: A linguagem da música existe na vida humana desde o nascimento, e as crianças precisam desenvolver um senso de ritmo. Os humanos têm maneiras diferentes de responder aos estímulos ambientais, incluindo o movimento. As crianças têm reações e gostos e estão prontas para aprender mais do que entendem. Precisamos analisar como podemos contribuir para a musicalização das crianças. A música contribui para o desenvolvimento cognitivo e motor, estimulando a criatividade. $\mathrm{O}$ dia-a-dia das crianças atende vários propósitos, incluindo ajudá-las a desenvolver hábitos, atitudes, disciplina. Partindo da hipótese de que a música pode influenciar o desenvolvimento cognitivo e motor infantil, este artigo buscou demonstrar que a música contribui significativamente para o desenvolvimento infantil por meio do estudo da literatura existente. Portanto, o artigo conclui que a música pode promover o desenvolvimento infantil, atrair mais atenção na sala de aula e estimular a criatividade e o movimento dos alunos.

Palavras- chave: Música. Movimento. Desenvolvimento Infantil.

ABSTRACT: The language of music has existed in human life from birth, and children need to develop a sense of rhythm. Humans have different ways of responding to environmental stimuli, including movement. Children have reactions and tastes and are ready to learn more than they understand. We need to analyze how we can contribute to the musicalization of children. Music contributes to cognitive and motor development, stimulating creativity. Children's daily lives serve several purposes, including helping them to develop habits, attitudes, discipline. Based on the hypothesis that music can influence child cognitive and motor development, this article sought to demonstrate that music significantly contributes to child development through the study of existing literature. Therefore, the article concludes that music can promote children's development, attract more attention in the classroom, and stimulate students' creativity and movement.

Keywords: Song. Movement. Child development.

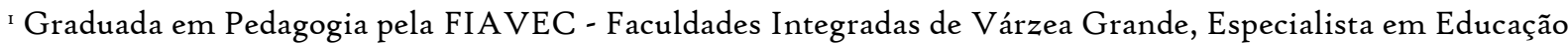
Infantil pela FIAVEC - Faculdades Integradas de Várzea Grande.

${ }^{2}$ Graduação em Pedagogia pelo UNIVAG - Centro Universitário, Especialista em Educação Infantil pela FAUC - Faculdade de Cuiabá.

${ }^{3}$ Graduação em Pedagogia pela UNIC - Universidade de Cuiabá.

${ }_{4}^{4}$ Graduação em Pedagogia pela UFMT - Universidade Federal de Mato Grosso, Especialista em Educação Infantil e Especial pela FIC - Faculdades Integradas de Cuiabá.
} 


\section{INTRODUÇÃO}

É necessário preocupar-nos em relação à formação das crianças, não apenas com o ensino dos conhecimentos sistematizados, mas também com o ensino de expressões, movimentos corporais e percepção (SILVA, 2010).

Ao oferecemos a música e um ambiente sonoro em diferentes situações, permitimos que bebês e crianças iniciem, intuitivamente, seu processo de musicalização. Escutando os diferentes sons de brinquedos, dos objetos, do ambiente e do próprio corpo, há observação, descoberta e reações (UNESCO, 2005).

A musicalização é um processo de construção do conhecimento, que objetiva despertar e desenvolver o gosto musical, favorece o desenvolvimento da sensibilidade, criatividade, senso rítmico, do prazer de ouvir música, da imaginação, memória, concentração, atenção, autodisciplina, do respeito ao próximo, da socialização e afetividade, também contribuindo para uma efetiva consciência corporal e de movimentação (BRÉSCIA, 2003).

As atividades de musicalização permitem que a criança conheça melhor a si mesma, desenvolvendo sua noção de esquema corporal, e também permitem a comunicação com o outro (CHIARELLI; BARRETO, 2005).

Os diferentes aspectos que a envolvem, além de promove comunicação social e integração, torna a linguagem musical uma importante forma de expressão humana e, por isso, deve ser parte do contexto educacional, principalmente na educação infantil (UNESCO, 2005).

É uma linguagem cujo conhecimento se constrói e não um produto pronto e acabado. Então a musicalização na escola é essencial. Traz alegria, descontração, entusiasmo, tudo o que se precisa para o trabalho escolar (LIMA, 20I0).

Através dessas ideias inicias é que surgiram os seguintes questionamentos acerca de como a música pode auxiliar no aprendizado das crianças? E qual tipo de música permite um melhor aprendizado?

Para responder a esses questionamentos, o presente artigo, teve como metodologia a pesquisa bibliográfica, buscou esclarecer o uso da música na educação infantil. 


\section{DESENVOLVIMENTO}

\section{I Música}

A música é vista por muitos como a primeira das artes, tanto no que diz respeito à história humana quanto ao seu valor na vida de todos nós. Para as civilizações primitivas, os sons tinham significado, o qual também estava presente em seus primitivos instrumentos. Ela é reconfortante e, auxilia o nosso equilíbrio emocional. Talvez isso ocorra devido à música nos remeter ao primeiro e mais importante som da vida: as batidas do coração de nossa mãe. O som uterino está gravado no inconsciente e simboliza proteção, aconchego e tranquilidade.

A música está presente em diversas situações e com diferentes objetivos, pois existe composições usadas para ninar, para dançar. Os países têm seus hinos, assim como as escolas e os times de futebol. Existem músicas típicas regionais. Inclusive, vemos hoje, em diversas maternidades, som ambiental nas salas de parto (UNESCO, 2005).

Segundo Bréscia (2003), a música é uma linguagem universal, tendo participado da história da humanidade desde as primeiras civilizações. Conforme dados antropológicos, as primeiras músicas seriam usadas em rituais, como: nascimento, casamento, morte, recuperação de doenças e fertilidade. Com o desenvolvimento das sociedades, a música também passou a ser utilizada em louvor a líderes, como a executada nas procissões reais do antigo Egito e na Suméria.

A música é a sucessão de sons e silêncio organizada ao longo do tempo. O ritmo, a melodia, o timbre e a harmonia, elementos constituintes da música, são capazes de afetar todo o organismo humano, de forma física e psicológica. Através de tais elementos o receptor da música responde tanto afetiva quanto corporalmente (FERREIRA, 2005).

O ritmo, de acordo com Le Bouch (1994) é a organização ou estruturação dos fenômenos temporais, sendo eles periódicos ou não. Todo ser humano é dotado de ritmo, que se manifesta antes mesmo do nascimento, através dos batimentos cardíacos, depois pela respiração e pela fala e que está presente também nas formas básicas de locomoção.

É o ritmo externo ao Homem que coloca em jogo, mais do que tudo, o movimento corporal e possíveis modificações fisiológicas. Autores e pesquisadores que conceituaram o ritmo admitem a dificuldade de situá-lo como algo concreto e a impossibilidade de defini-lo 
e de avaliá-lo de forma objetiva. Poderíamos considerar que o ritmo é um fenômeno que existe de fato (TIBEAU, 2006).

Entender o ritmo como algo interno e que pode ser alterado a partir de estímulos externos, advindos do meio ambiente, é considerá-lo como impulsionador de processos psíquicos, afetivos e emocionais.

O ritmo está presente em todas as manifestações da motricidade humana, é universal e o percebemos em todos os movimentos da vida (TIBEAU, 2006).

Zampronha (2002) considera que o ritmo possibilita ao indivíduo tomar consciência de seu corpo.

A correlação entre movimento e ritmo, citada por Camargo (1994) é que: "O movimento, com todas as suas implicações físicas, emocionais e mentais, é um fenômeno dotado de organização, que se evidencia no espaço, no tempo e sob determinado ritmo”.

Assim, ritmo e movimento humano se desenvolvem simultaneamente no tempo e no espaço, confirmando a consideração de que o ritmo é movimento, que o movimento é ritmo e que ambos estão ligados à percepção temporal, espacial e proprioceptiva (TIBEAU, 2006).

No entender de Fonseca (1996) o ritmo e a música, assim como o movimento, devem ser vistos de dentro para fora, na medida em que não há movimento, música e ritmo para as pessoas, mas sim pessoas que se movem, que vivem e sentem a música e o movimento.

\subsection{A música no desenvolvimento infantil}

A linguagem musical está presente na vida dos seres humanos e há muito tempo faz parte da educação de crianças e adultos. Desde o nascimento, a criança tem necessidade de desenvolver o senso de ritmo, pois o mundo que a rodeia, expressa numa profusão de ritmos evidenciados por diversos aspectos: no relógio, no andar das pessoas, no voo dos pássaros, nos pingos de chuva, nas batidas do coração, numa banda, num motor, no piscar de olhos e até mesmo na voz das pessoas mais próximas.

É necessário contemplar e analisar que tipo de contribuição pode ocorrer com o trabalho de musicalização para bebês, como isso pode acontecer e as influências que a mesma pode proporcionar na formação do desenvolvimento futuro dos seres humanos. Pesquisas em diversas áreas do conhecimento enfocam a contribuição da música no desenvolvimento 
infantil, procurando conhecer e analisar as ações e reações dos bebês ainda na gestação, logo após o nascimento e no período sensório-motor (FERREIRA et al, 2007).

Tanto Ilari (2003) como Beyer (1988) referem-se a diversos trabalhos que notificaram que bebês expostos à música durante a gravidez exibem mudanças nos batimentos cardíacos e nos movimentos corporais quando ouvem a mesma música após o nascimento, o que indica que eles a reconhecem.

Ao longo dos primeiros anos de vida, o bebê apresenta um ritmo de desenvolvimento muito acelerado (PAPALIA, OLDS, FELDMAN, 2006), sendo os ganhos desenvolvimentais potencializados em função da maior plasticidade cerebral e aumento das redes neurais (GABBARD, 1998). Os principais movimentos que o indivíduo apresenta nessa fase são os movimentos reflexos, as estereotipias e os movimentos voluntários (GALLAHUE, OZMUN, 2005; HAYWOOD, GETCHELL, 2004; PAYNE, ISAACS, 2007).

Os movimentos reflexos são respostas físicas automáticas desencadeadas involuntariamente por um estímulo específico. (BEE, 2003). Outra categoria de movimento observada nos bebês são as estereotipias, que são movimentos rítmicos, padronizados, relativamente invariáveis e submetidos a um controle central. Esses movimentos são considerados benéficos para o desenvolvimento posterior, acredita-se que eles componham uma fase de transição entre a atividade reflexa e voluntária (PAYNE, ISAACS, 2007).

Os bebês apresentam reações e preferências, e estão prontos para aprender muito mais do que se costumava pensar (BEYER, 1988). Este aspecto vem sendo discutido com a preocupação em melhorar a qualidade da educação musical e aproveitar os meios de trabalhar-se com eles, já que os bebês são receptivos e seu potencial de aprendizado vai além da concepção do educador (MARTINS, 2004).

Para Jeandot (1997) o som prende a atenção das crianças e o contato com o objeto viabiliza a interação com o mundo sonoro, pois o objeto produz sons e desperta à criança para atitudes de gestos variados. Como recurso auditivo a música está presente desde o nascimento da criança e estará contribuindo no seu desenvolvimento e compreensão do mundo. 
A música no dia-a-dia das crianças vem atendendo a diversos objetivos como suporte para a formação de hábitos, atitudes, disciplina, condicionamento da rotina, comemorações de datas diversas etc. Assim o emprego de diferentes tipos de música é uma questão vinculada a cada situação, mas muitas vezes e sempre acompanhadas de gestos e movimentos que pela repetição se torna mecânicos e estereotipadas (GÓES, 2009).

O Desenvolvimento Motor, especificamente, consiste nas mudanças no comportamento motor ao longo da vida, progredindo de movimentos simples até a realização de tarefas motoras altamente especializadas (GALLAHUE, OZMUN, 2005).

A música tem sua contribuição para o desenvolvimento cognitivo e motor despertando a criatividade. Cada criança ao escutar uma melodia, interpreta-a de forma única e pessoal. Além da forma de internalização, inversamente, a música fornece, também subsidio para externalizar sentimentos.

As diferentes situações contidas nas brincadeiras que envolvam música fazem a criança crescer através da procura de soluções e de alternativas. O desempenho psicomotor da criança enquanto brinca alcança níveis que só mesmo com a motivação ela consegue. Ao mesmo tempo favorece a concentração, a atenção, o engajamento e a imaginação. Como consequência a criança fica mais calma relaxada e aprende a pensar, estimulando sua inteligência (GÓES, 2009).

Através da música o ser humano consegue uma forma de expressar-se sentimentalmente, traz consigo a possibilidade de exteriorizar as alegrias, as tristezas e as emoções mais profundas, emergindo emoções e sentimentos que as palavras são muitas vezes incapazes de evocar (LIMA, 2010).

Beyer (1988); Feres (1998) e Ilari (2002) consideram a música importante no primeiro ano de vida, como colaboradora no desenvolvimento musical propriamente dito, mas também no desenvolvimento cognitivo, nas habilidades motoras, linguísticas e na percepção auditiva.

Dessa forma a música precisa ser considerada uma verdadeira "linguagem de expressão", parte integrante da formação global da criança influenciando no desenvolvimento dos processos de aquisição do conhecimento, sensibilidade, sociabilidade e criatividade. 
A música no dia-a-dia das crianças vem atendendo a diversos propósitos como suporte para a formação de hábitos, atitudes, disciplina, condicionamento da rotina, comemorações de datas diversas etc. Assim o emprego de diferentes tipos de música é uma questão vinculada a cada situação, mas muitas vezes e sempre acompanhadas de gestos e movimentos que pela repetição se torna mecânicos e estereotipadas (GÓES, 2009).

Com as crianças em idade pré-escolar convém enfatizar a liberação do instinto rítmico, principalmente por meio da expressão corporal de uma forma criativa e espontânea e da utilização de exercícios rítmicos, com acompanhamento do ritmo de canções (FERREIRA et al, 2007).

$\mathrm{O}$ ser humano tem várias maneiras de responder aos estímulos do meio ambiente, $\mathrm{e}$ o movimento é uma delas. Segundo Ferraz (1987) apud Ferreira et al, (2007, p. 12) "Utilizamos nosso universo interior perceptivo e cognitivo ideológico a fim de que se processe a leitura através do diálogo entre nós e o objeto lido”.

O corpo expressa sensações, emoções, sentimentos e pensamentos. A linguagem corporal afirma o conceito do ser humano expressando a si mesmo, ele é seu próprio instrumento. A linguagem do corpo conscientiza-se na dança, na mímica, na ginástica, nas dramatizações, nos jogos e na expressão teatral. A dança é a expressão corporal da poesia latente em todo ser humano.

\subsection{O desenvolvimento físico e a música}

Para Bréscia (2003) a musicalização é um processo de construção do conhecimento, que tem como objetivo despertar e desenvolver o gosto musical, favorecendo o desenvolvimento da sensibilidade, criatividade, senso rítmico, do prazer de ouvir música, da imaginação, memória, concentração, atenção, autodisciplina, do respeito ao próximo, da socialização e afetividade, também contribuindo para uma efetiva consciência corporal e de movimentação.

As atividades de musicalização possibilitam que a criança conheça melhor a si mesma, desenvolvendo sua noção de esquema corporal, e também permitem a comunicação com o outro. Weigel (1988) e Barreto (2000) afirmam que atividades podem contribuir de 
maneira indelével como reforço no desenvolvimento cognitivo/ linguístico, psicomotor e sócio-afetivo da criança, da seguinte forma:

- Desenvolvimento cognitivo/ linguístico: a fonte de conhecimento da criança são as situações que ela tem oportunidade de experimentar em seu dia a dia. Nesse sentido, as experiências com rítmicos musicais permitem uma participação ativa favorece o desenvolvimento dos sentidos das crianças. Ao trabalhar com os sons ela desenvolve sua acuidade auditiva; ao acompanhar gestos ou dançar ela está trabalhando a coordenação motora e a atenção; ao cantar ou imitar sons ela está descobrindo suas capacidades e estabelecendo relações com o ambiente em que vive.

- Desenvolvimento psicomotor: as atividades musicais oferecem inúmeras oportunidades para que a criança aprimore sua habilidade motora, aprenda a controlar seus músculos e mova-se com desenvoltura. O ritmo tem um papel importante na formação e equilíbrio do sistema nervoso. Isto porque toda expressão musical ativa age sobre a mente, favorecendo a descarga emocional, a reação motora e aliviando as tensões. Atividades como cantar fazendo gestos, dançar, bater palmas, pés, são experiências importantes para a criança, pois elas permitem que se desenvolva o senso rítmico, a coordenação motora, fatores importantes também para o processo de aquisição da leitura e da escrita.

- Desenvolvimento sócio-afetivo: a criança aos poucos vai formando sua identidade, percebendo-se diferente dos outros e ao mesmo tempo buscando integrar-se com os outros. Através do desenvolvimento da autoestima ela aprende a se aceitar como é, com suas capacidades e limitações.

As atividades musicais coletivas favorecem o desenvolvimento da socialização, estimulando a compreensão, a participação e a cooperação. Dessa forma a criança vai desenvolvendo o conceito de grupo. Além disso, ao expressar-se musicalmente em atividades que lhe deem prazer, ela demonstra seus sentimentos, libera suas emoções, desenvolvendo um sentimento de segurança e auto-realização (CHIARELLI; BARRETO, 2005).

Bréscia (2003) ressalta que os jogos musicais podem ser de três tipos, correspondentes às fases do desenvolvimento infantil: 
- Sensório-Motor: São atividades que relacionam o som e o gesto. A criança pode fazer gestos para produzir sons e expressar-se corporalmente para representar o que ouve ou canta.

- Simbólico: Aqui se busca representar o significado da música, o sentimento, a expressão. O som tem função de ilustração, de sonoplastia.

- $\quad$ Analítico ou de Regras: São jogos que envolvem a estrutura da música, onde são necessárias a socialização e organização. Ela precisa escutar a si mesma e aos outros, esperando sua vez de cantar ou tocar (CHIARELLI; BARRETO, 2005).

A música, através de suas características intrínsecas, pode colaborar no desenvolvimento das estruturas cognitivas, bem como favorecer o desenvolvimento de outras habilidades, como as emocionais, as sociais e as musicais, propriamente ditas (MARTINS, 2004).

Delalande apud Pires (2005), diz que desde os primeiros dias da vida, elas são atraídas pelos sons musicais e manifestando-se de várias maneiras, sorrisos, interagindo com os sons através dos movimentos corporais, como palmas e toques nos brinquedos sonoros.

A música está bastante ligada ao lúdico e ao brincar. Em todos os povos, as crianças brincam com a música. Jogos e brinquedos musicais, como as rodas cantadas, são encontrados nos lugares aonde houver crianças (UNESCO, 2005).

Rosa (1990) destaca que a importância do educador em proporcionar momentos onde a criança descubra, analise e compreenda os ritmos do mundo, através da observação e do contato com instrumentos musicais, com a dança, com o folclore, etc. Deve estar atento a valorizar todas as formas de expressão escolhidas pelas crianças, pois a mesma comunica-se principalmente através do corpo.

No interior do Brasil existem inúmeras danças, cantigas de roda e ciranda que incentivam movimentos de diferentes qualidades expressivas e rítmicas realizada em grupo, que possuem um profundo sentido socializador, estético e transcendente, mas que, ainda não são devidamente valorizados no cotidiano das escolas. Estas músicas que cantam histórias dançam mitos e falam da memória e da alegria do povo são rituais vivenciados por todas as idades que podem se tornar o vínculo afetivo e cultural entre a escola e a comunidade (GÓES, 2009). 


\subsection{A música no desenvolvimento infantil}

O gesto e o movimento corporal estão conectados à música, porque o som é também gesto e movimento vibratório, e o corpo traduz os diferentes sons que percebe através dos movimentos de balanço, flexão, andar, saltar, etc. Quando ouve um impulso sonoro e realiza um movimento corporal intencional, a criança está transpondo o som percebido para outra linguagem, muitas vezes a da dança.

Quando oferecemos música e um ambiente sonoro em diferentes situações, permitimos que bebês e crianças iniciem, intuitivamente, seu processo de musicalização. Escutando os diferentes sons de brinquedos, dos objetos, do ambiente e do próprio corpo, há observação, descoberta e reações, mesmo nos bebês (UNESCO, 2005).

Nos berçários, brincadeiras que envolvem música, canto e movimento possibilitam a percepção rítmica, mesmo porque os bebês produzem ruídos e balbucios desde recémnascidos. Proporcione diversas situações e experiências de explorações e descobertas tanto sonoras quanto musicais para os bebês.

Até por volta de um ano e meio, a criança mais nos ouve do que canta, no entanto, já

demonstra suas preferências e as acompanha de algum modo. Em um segundo momento, canta os finais das frases ou as partes preferidas e, muitas vezes, um pouco depois de nós. A partir dos 3 anos, a criança já entoa todo o repertório de seu meio, cantando integralmente muitas das músicas conhecidas.

Assim como no desenvolvimento musical, quanto mais as crianças tiverem oportunidade de vivenciar situações em que possam se expressar pela dança, mais naturalmente usarão essa linguagem (UNESCO, 2005).

Brito (2003), nos fala que é difícil encontrar alguém que não se relacione com a música [...] Surpreendemo-nos cantando aquela canção que parece ter "cola" e que não sai da nossa cabeça e não resistimos a, pelo menos, mexer os pés, reagindo a um ritmo envolvente [...].

Atividades como cantar fazendo gestos, dançar, bater palmas, pés, são experiências importantes para a criança, pois elas permitem que se desenvolva o senso rítmico, a coordenação motora, sendo fatores importantes também para o processo de aquisição da leitura e da escrita. (CHIARELLI; BARRETO, 2005) 


\subsection{A música e educação escolar}

É necessário preocupar-nos em relação à formação das crianças, não apenas com o ensino dos conhecimentos sistematizados como Português, Matemática, História, Geografia e Ciências, mas também com o ensino de expressões, movimentos corporais e percepção (SILVA, 2010).

Pacheco (199I) e Ponso (2008) defendem a escola como lugar de aprendizagem significativa e apresentam o recurso musical como um símbolo valoroso no aprendizado dos alunos de anos iniciais do ensino fundamental, que conhecem este recurso auditivo, mas não o utiliza de forma racional e sistematizada.

A música no contexto da Educação Infantil vem, ao longo de sua história, atendendo a vários objetivos. Tem sido em muitos casos, suporte para atender a vários propósitos, como a formação de hábitos, atitudes e comportamentos, a realização de comemorações relativas ao calendário de eventos do ano letivo, a memorização de conteúdos, todos traduzidos em canções. Essas canções costumam ser acompanhadas por gestos corporais, imitados pelas crianças de forma mecânica e estereotipada (FERREIRA et al, 2007).

A Educação Infantil no seu dia-a-dia vivencia muitas atividades musicais, pois desde a chegada da criança na creche ou na escola infantil esta é recebida com músicas que alegram o ambiente e faz com que a criança possa desejar permanecer na sala de aula (CHIARELLI; BARRETO, 2005).

A música possui diversos significados e representações no dia-a-dia das pessoas e se empregada de modo adequada pode ser um agente facilitador em diversos contextos que envolvam o raciocínio e a aprendizagem. Sabe-se que a música tem um papel relevante na educação infantil. Pois o envolvimento da criança com o universo sonoro começa ainda antes do nascimento (GÓES, 2009).

$\mathrm{Na}$ Educação Infantil, o contato com pessoas diferente do meio familiar permite que ela estabeleça novas relações e adquira novos conhecimentos. Convém fazer a criança descobrir o folclore em suas próprias manifestações, relacionando-as com as manifestações das outras crianças. As canções folclóricas têm como características a autoria 
anônima, a aceitação coletiva que conduz à criação de variantes, a transmissão oral, a tradicional.

Ladainhas para saltar corda são pequenos versos que acompanham ritmicamente o ato de pular corda. Pertencem à cultura popular infantil e passam de geração para geração através da atividade lúdica e espontânea das crianças. Deve-se resgatá-las, enquanto recurso pedagógico de obtenção de alguns dos objetivos da Educação Física Escolar.

Ponso (2008) diz que o uso da música no universo literário, através de poemas, parlendas, lendas, fábulas, quadrinha, trava-língua, provérbios, advinha e histórias infantis. No momento do desenho, da alfabetização, da escrita, da leitura, da fala, do desenvolvimento motor, dos conhecimentos de novos saberes, a música será um recurso sonoro que irá contribuir na construção do conhecimento da criança através das vibrações e da aplicabilidade que linguagem musical permite produzir.

Diversas áreas do conhecimento podem ser estimuladas com a prática da musicalização. Pois, ela atende diferentes aspectos do desenvolvimento humano: físico, mental, social, emocional e espiritual, podendo a música ser considerada um agente facilitador do processo educacional (SOUSA; VIVALDO, 2010).

A música está presente em todas as culturas e pode ser utilizada como fator determinante nos desenvolvimentos motor, linguístico e afetivo de todos os indivíduos (MARTINS, 2004).

Os diferentes aspectos que a envolvem, além de promoverem comunicação social e integração, tornam a linguagem musical uma importante forma de expressão humana e, por isso, deve ser parte do contexto educacional, principalmente na educação infantil (UNESCO, 2005).

Através da música o educador tem uma forma privilegiada de alcançar seus objetivos, podendo explorar e desenvolver características no aluno. $\mathrm{O}$ indivíduo com a educação musical cresce emocionalmente, afetivamente e cognitivamente, desenvolve coordenação motora, acuidade visual e auditiva, bem como memória e atenção, e ainda criatividade e capacidade de comunicação (LIMA, 2010).

Ao inserir-se a música na prática diária do ambiente educativo, a mesma pode tornar-se um importante elemento auxiliador no processo de aprendizagem da escrita e da 
leitura criando o gosto pelos diversos assuntos estudados, desenvolvendo a coordenação motora, o ritmo, auxiliando na formação de conceitos, no desenvolvimento da autoestima e na interação com o outro.

Segundo Martins (1985, p. 47) educar musicalmente é propiciar à criança uma compreensão progressiva da linguagem musical, através de experimento e convivências orientadas. O conhecimento é construído a partir da interação da criança com o meio ambiente, e o ritmo é parte primordial do mundo que o cerca.

Os recursos pedagógicos são elementos práticos para operacionalizar o ensino. Podemos citar os recursos naturais, audiovisuais, visuais, auditivos e estruturais como componentes auxiliadores do momento de ensino/aprendizagem. A música é um recurso auditivo, que pode contribuir com a proposta de ensino do professor, de maneira interativa às disciplinas. (GÓES, 2009)

A linguagem musical deve estar presente no contexto educativo, envolvendo atividades e situações desafiadoras e significativas que favoreçam a exploração, a descoberta e a apropriação de conhecimento. A ludicidade evidenciada nas atividades de sala de aula ou até de Educação Física possibilita que o professor oportunize a criança um programa de atividades motoras (FERREIRA et al, 2007).

Do ponto de vista pedagógico, as músicas são consideradas completas: brincando com músicas as crianças exercitam naturalmente o seu corpo, desenvolvem o raciocínio e a memória, estimulam o gosto pelo canto (GÓES, 2009).

Cada vez mais instituições educacionais estão utilizando a música como eixo norteador do processo de alfabetização. A música atrai e envolve as crianças, serve como motivação, eleva a autoestima, estimula diferentes áreas do cérebro, aumenta a sensibilidade, a criatividade, à capacidade de concentração e fixação de dados (GÓES, 2009).

A presença da música na educação auxilia a percepção, estimula a memória e a inteligência, relacionando-se ainda com habilidades linguísticas e lógico-matemáticas ao desenvolver procedimentos que ajudam o educando a se reconhecer e a se orientar melhor no mundo. Além disso, a música também vem sendo utilizada como fator de bem-estar no trabalho e em diversas atividades terapêuticas, como elemento auxiliar na manutenção e recuperação da saúde (CHIARELLI; BARRETO, 2005). 
As atividades musicais nas escolas devem partir do que as crianças já conhecem desta forma, se desenvolve dentro das condições e possibilidades de trabalho de cada professor. (SCAGNOLATO, 2009). É importantíssima, porém faz-se necessário ressaltar que deve ser direcionada, para não ser apenas uma aula de curtição (LIMA, 20Io).

As atividades de musicalização também favorecem a inclusão de crianças portadoras de necessidades especiais. Pelo seu caráter lúdico e de livre expressão, não apresentam pressões nem cobranças de resultados, são uma forma de aliviar e relaxar a criança, auxiliando na desinibição, contribuindo para o envolvimento social, despertando noções de respeito e consideração pelo outro, e abrindo espaço para outras aprendizagens (CHIARELLI; BARRETO, 2005).

A música não substitui o restante da educação, ela tem como função atingir o ser humano em sua totalidade. A educação tem como meta desenvolver em cada indivíduo toda a perfeição de que é capaz. Porém, sem a utilização da música não é possível atingir a esta meta, pois nenhuma outra atividade consegue levar o indivíduo a agir. A música atinge a motricidade e a sensorialidade por meio do ritmo e do som, e por meio da melodia, atinge a afetividade (SCAGNOLATO, 2006).

A música é importante para trabalhar temas atuais, assim o aluno desperta o senso crítico, analisando a letra da música. Relacionando-as com a realidade da sociedade (LIMA, 2010).

As atividades desenvolvidas em aulas de musicalização, em geral podem auxiliar no desenvolvimento do cérebro, cabendo ao educador pesquisar, planejar, diagnosticar e ajudar o aluno a desenvolver a inteligência musical e construir seu conhecimento vivenciando as diversas formas de "fazer música" (MARTINS, 2004).

A música no cotidiano escolar pode não somente ajudar as crianças no aprendizado, mas também nos casos de crianças que tenham problemas de relacionamento ou inibição, para isso é preciso aliar música e movimento (SOUSA; VIVALDO, 2010).

\section{CONCLUSÃO}

O presente artigo trata da importância da música na educação infantil, sua contribuição para o desenvolvimento da criança. As músicas que devem ser usadas para melhor aproveitamento na educação e no desenvolvimento infantil. 
A música faz parte da vida humana desde o nascimento, todos os sons do ambiente são música para os bebês, estando presente também, na cultura dos povos, nas crenças, danças e também nas brincadeiras. Favorece o desenvolvimento dos movimentos, da linguagem, da sociabilidade, além de acalmar. Isso deve ser utilizado na educação infantil, no auxílio para um desenvolvimento mais rápido e mais eficaz.

$\mathrm{Na}$ educação infantil, as músicas muitas vezes são utilizadas para criar hábitos, como lavar as mãos, hora do lanche, entre outros, favorece para a educação da criança, além de estimular a sociabilidade. Ao oferecer o estímulo rítmico da criança, desenvolve sua linguagem corporal para expressar a música que ouve.

A música contribui no desenvolvimento da criança, intelectual quanto físico, portanto deve ser usada músicas com ritmos fáceis de acompanhar com palmas, gestos e expressões corporais, para que a criança possa desenvolver suas capacidades.

Pode-se concluir através deste artigo que a música é mais uma ferramenta para facilitar o desenvolvimento da criança, sendo utilizada de modo correto, e estimulando a criança poderemos ter um desenvolvimento facilitado, além de crianças mais sociáveis e mais tranquilas.

\section{REFERÊNCIAS BIBLIOGRÁFICAS}

BARRETO, S. de J. Psicomotricidade: educação e reeducação. 2ª ed. Blumenau: Acadêmica, 2005 .

BEE, H. A criança em desenvolvimento. 9aㅡ ed. Porto Alegre: Artmed, 2003.

BEYER, E. S. W. A abordagem cognitiva em música: uma crítica ao ensino da música, a partir da teoria de Piaget. Rio Grande do Sul, 1988 Dissertação de Mestrado em Educação. Universidade Federal do Rio Grande do Sul, 1988.

BRÉSCIA, V. L. P. Educação Musical: bases psicológicas e ação preventiva. São Paulo: Átomo, 2003.

BRITO, T. A. de. Música na educação infantil: propostas para a formação integral da criança. $3^{\underline{a}}$ ed. São Paulo: Petrópolis, 2003.

CAMARGO, M. L. M. de. Música/Movimento: um universo em duas dimensões: aspectos técnicos e pedagógicos na educação física. Belo Horizonte: Villa Rica, 1994. 
CHIARELLI, L. K. M.; BARRETO, S. DE J. A importância da musicalização na educação infantil e no ensino fundamental: a música como meio de desenvolver a inteligência e a integração do ser. Revista Recre@rte.n. 3, 2005.

FERES, J. S. M. Bebê, Música e movimento. São Paulo: Ricordi, 1998.

FERREIRA, D. L. DE A.; GOES, T. A.; PARANGABA, C. DE O.; SILVA, M. DA R.; FERRO, O. M. DOS R. A Influência Da Linguagem Musical Na Educação Infantil. In: jornada do HISTEDBR, 7, 2007, Campo Grande. Anais da VII Jornada do HISTEDBR História, Sociedade e Educação no Brasil, Campo Grande, 2007.

FERREIRA, T. T. Música para se ver. 2005. Monografia apresentada na disciplina de Projetos experimentais - Universidade Federal de Juiz de Fora: FACOM - Faculdade de Comunicação, 2005.

GAllAHUE, D. L.; OZMUN, J. C. Compreendendo o Desenvolvimento Motor: bebês, crianças, adolescentes e adultos. $3^{\mathrm{a}}$ edição. São Paulo: Phorte, 2005.

GÓES, R. S. A música e suas possibilidades no desenvolvimento da criança e do aprimoramento do código linguístico. Revista do Centro de Educação a Distância CEAD/UDESC. v.2, n. I, 2009.

HAYWOOD, K. M.; GETCHELL, N. Desenvolvimento motor ao longo da vida. $3^{\underline{a}}$ ed. Porto Alegre: Artes Médicas, 2004.

ILARI, B. Bebês também entendem de música: a percepção e a cognição musical no primeiro ano de vida. Revista da ABEM Associação Brasileira de Educação musical. Porto Alegre, n. 7, p. 83-90, 2002.

ILARI, B. Cognição musical e educação musical: Integrando teoria e prática. In. XII Encontro da ABEM Associação Brasileira de Educação musical. Universidade Federal do Paraná, Curitiba, 2003.

LIMA, S. V. de. A Importância da Música no Desenvolvimento Infantil. Artigonal Diretório de Artigos Gratuitos. 2010.

MARTINS, R. Educação musical: conceitos e preconceitos. Rio de Janeiro: FUNARTE Instituto Nacional de Música, 1985.

MARTINS, R. P. L. Contribuição da música no desenvolvimento das habilidades motoras e da linguagem de um bebê: um estudo de caso. 2004. Monografia apresentada para obtenção do título de Especialista em Educação Musical e Canto Coral-Infanto Juvenil do Curso de Pós-graduação da Escola de Música e Belas Artes do Paraná. Londrina - PR, 2004.

PACHECO, E. D. Comunicação, educação e arte na cultura infanto-juvenil. São Paulo: Edições Loyola, 1991. 
PAPALIA, D. E.; OLDS, S. W.; FELDMAN, R. D. Desenvolvimento Humano. 8ª edição. Porto Alegre: Artmed, 2006.

PAYNE, V. G.; ISAACS, L. D. Desenvolvimento Motor Humano: uma abordagem vitalícia. Rio de Janeiro: Guanabara Koogan, 2007.

PIRES, M. C. de C. O som como linguagem e manifestação da primeira infância. Revista Pátio Educação Infantil, n.8, 2005.

PONSO, C. C. Música em diálogo: ações interdisciplinares na Educação Infantil. Porto Alegre: Sulina, 2008.

ROSA, L. S. S. Educação musical para a pré-escola. São Paulo: Ática, 1990.

SCAGNOLATO, L. A. de S.A Importância da Música no Desenvolvimento Infantil. Webartigos, 2009.

SILVA, D. G. da. A importância da música no processo de aprendizagem da criança na educação infantil: uma análise da literatura. 2010. Trabalho de Conclusão de Curso (Graduação em Pedagogia) - Universidade Estadual de Londrina, Londrina, 2010.

SOUSA, J. V. DE; VIVALDO, L. A importância da música na Educação Infantil. P@rtes Revista Eletrônica. 2010.

WEIGEL, A. M. G. Brincando de Música: Experiências com Sons, Ritmos, Música e Movimentos na Pré-Escola. Porto Alegre: Kuarup, 1988.

ZAMPRONHA, M. L. Da música, seus usos e recursos. São Paulo: UNESP, 2002. 